University of Nebraska - Lincoln

DigitalCommons@University of Nebraska - Lincoln

Sociology Department, Faculty Publications

Sociology, Department of

2011

\title{
Effect of School Racial Composition on Trajectories of Depressive Symptoms from Adolescence Through Early Adulthood
}

\author{
Katrina M. Walsemann \\ University of South Carolina - Columbia, kwalsema@sc.edu \\ Bethany A. Bell \\ University of South Carolina - Columbia, bellb@mailbox.sc.edu \\ Bridget J. Goosby \\ University of Nebraska-Lincoln, bgoosby2@unl.edu
}

Follow this and additional works at: https://digitalcommons.unl.edu/sociologyfacpub

Part of the Sociology Commons

Walsemann, Katrina M.; Bell, Bethany A.; and Goosby, Bridget J., "Effect of School Racial Composition on Trajectories of Depressive Symptoms from Adolescence Through Early Adulthood" (2011). Sociology Department, Faculty Publications. 167.

https://digitalcommons.unl.edu/sociologyfacpub/167

This Article is brought to you for free and open access by the Sociology, Department of at DigitalCommons@University of Nebraska - Lincoln. It has been accepted for inclusion in Sociology Department, Faculty Publications by an authorized administrator of DigitalCommons@University of Nebraska - Lincoln. 
Published in Race and Social Problems 3 (2011), pp. 131-145; doi: 10.1007/s12552-011-9053-3

Copyright ( 2011 Springer Science+Business Media, LLC. Used by permission.

Published online August 31, 2011.

\title{
Effect of School Racial Composition on Trajectories of Depressive Symptoms from Adolescence Through Early Adulthood
}

\author{
Katrina M. Walsemann, Bethany A. Bell, and Bridget J. Goosby
}

\begin{abstract}
We investigate the effect of high school racial composition, measured as percent of non-Hispanic white students, on trajectories of depressive symptoms from adolescence to early adulthood. We also explore whether the effect of school racial composition varies by respondent race/ethnicity and whether adult socioeconomic status mediates this relationship. We analyzed four waves of data from the National Longitudinal Study of Adolescent Health using 3-level linear growth models. We restricted our sample to respondents enrolled in grades 9-12 in 1994/5 who were interviewed at a minimum in Waves I and IV. This resulted in 10,350 respondents enrolled in 80 high schools in 1994/5 (5,561 whites, 2,030 blacks, 1,834 Hispanics, 738 Asians, and 187 of other race). As the percentage of white students increased at the high school respondents attended in 1994/5, blacks reported more depressive symptoms. This effect did not vary by age. In comparison, Asian and Hispanic respondents who attended predominantly white high schools had lower levels of depressive symptoms than their counterparts who attended predominantly minority schools, but they also experienced a slower decline in depressive symptoms through early adulthood. Adult SES mediated the relationship between high school racial composition and depressive symptoms for black, but not for Asian or Hispanic respondents. Our results suggest that high school racial composition is associated with trajectories of depressive symptoms through early adulthood, but the effect differs by respondents' race/ethnicity. Racial/ethnic disparities in depressive symptoms during early adulthood may have their origins in adolescence.
\end{abstract}

Keywords: school segregation, mental health, racial disparities, school contexts

\section{Introduction}

A growing body of research exists that examines the effects of school segregation and school racial composition on adolescent health and health behaviors (Johnson and Hoffmann 2000; Botticello 2009; Walsemann and Bell 2010; Walsemann et al. 2011). A few of these studies have examined the interactive effect between student race and school racial composition and have generally found that for black adolescents, attending predominantly minority schools is associated with better physical and mental health (Walsemann et al. 2011) as well as a lower likelihood of engaging in some risky behaviors (Johnson and Hoffmann 2000). These findings mirror those conducted by neighborhood researchers who often find a group density effect such that health is better for residents when they live in neighborhoods where they are the numerical majority (Pickett and Wilkinson 2008). Most of the research on school racial composition has been cross-sectional; therefore, we know little about how school racial composition impacts health

K. M. Walsemann (Corresponding author)

Department of Health Promotion, Education, and Behavior, University of South Carolina, 800 Sumter Street, Room 216, Columbia, SC 29208, USA e-mail: kwalsema@sc.edu

\section{B. A. Bell}

Educational Psychology, Research, and Foundations Program, University of South Carolina, 820 Main Street, Room 133, Columbia, SC 29208, USA

\section{B. J. Goosby}

Department of Sociology, University of Nebraska-Lincoln, 711 Oldfather Hall, Lincoln, NE 68588-0324, USA 
as individuals age, even though schools are one of the strongest socializing forces in the United States (Hallinan 2001). We seek to address this limitation by investigating whether school racial composition influences trajectories of depressive symptoms from adolescence through early adulthood among a representative sample of individuals who attended US high schools in 1994/5, whether the effect of school racial composition on trajectories of depressive symptoms varies by respondent race/ethnicity, and whether discrimination, school attachment, and adult socioeconomic status (SES) mediate the relationship.

\section{Background}

Adolescence is a time of significant change and as such, what occurs during adolescence can have long-term impacts on individuals' social, economic, and health trajectories. In this study, we employ a life course perspective to understand trajectories of depressive symptoms (Elder et al. 2003; George 2007); this perspective posits that social environments experienced during key developmental periods can have pronounced effects on health not only at the time of exposure, but over the life course (Avison 2010). This may be especially true when it comes to mental health, as prior studies have found that childhood SES (Harper et al. 2002; Adkins et al. 2009; Walsemann et al. 2009), educational inequalities (Walsemann et al. 2009), and childhood adversities (Kessler et al. 1997; Thoits 2010) increase the risk of depressive symptoms, mood disorders, and other psychological problems in adulthood.

We focus on the school environment given that the US educational system plays a fundamental role in processes of social mobility. Although the educational system is expected to provide a level playing field, with only individual talent and effort distinguishing those who succeed from those who fail, it often does not (Hochschild and Scovronick 2003). In fact, some have argued that schools perpetuate and reproduce social and racial inequalities (Bourdieu 1973; Lewis 2003; Rubin 2008). Schools do this through a variety of mechanisms, including the power structure within schools (e.g., whites in positions of power), the use of racial code words (e.g., "urban," "ghetto"), and the legitimization of cultural resources (e.g., "middle class values," "forms of interactions") as indicators of knowledge and aptitude (Mickelson 2001; Lewis 2003; Rubin 2008).

The school environment may therefore contribute to psychosocial experiences that can increase or decrease the likelihood of psychological problems during adolescence and adulthood (Avison 2010). Black and Hispanic students are at greater risk of experiencing discrimination within predominantly white schools than within predominantly minority schools (Feagin et al. 1996; McCabe 2009; Walsemann et al. 2011). For example, Feagin et al. (1996) found that black college students attending predominantly white US universities reported differential treatment from professors and students, such as insensitivity to black culture, holding stereotypic views about black academic competence, and verbal harassment. Conversely, studies have found that Asian American adolescents who attend more ethnically diverse schools are at higher risk of experiencing discrimination relative to their black and Hispanic peers (Conchas and Perez 2003; Rosenbloom and Way 2004). There are serious health consequences of discrimination; discrimination is associated with psychological distress, depressive symptoms, and major depression (Pavalko et al. 2003; Williams et al. 2003; Schulz et al. 2006). Moreover, adolescents who perceive discriminatory treatment by teachers or staff are at greater risk of experiencing declining mental health (Roeser et al. 2000) and higher levels of depressive symptoms (Juang and Cookston 2009; Walsemann et al. 2011).

Schools also perpetuate and reproduce social and racial inequalities through the use of policies that serve to sort and separate students under the guise of meritocracy. For example, within racially mixed and predominantly white schools, administrators, teachers, and parents often use race/ethnicity as a marker of ability (Oakes et al. 1997; Lewis 2003); black and Hispanic students are more likely than whites to be tracked into less academically rigorous coursework even at equivalent ability levels (Darling-Hammond 2004; Mickelson and Everett 2008). In this way, students' race/ethnicity serves as a form of symbolic capital - it establishes "differences and distinctions in the form of binary oppositions ... [and is] a classification system built upon the fundamental logic of inclusion and exclusion" (Swartz 1997, p. 84).

Thus, the racial composition of schools may create an environment of inclusion for some, but exclusion for others (Feagin et al. 1996; Yonezawa et al. 2002; Lewis 2003). Because predominantly white schools often fail to adequately incorporate the values, interests, or history of people of color into the curriculum and school culture, black and Hispanic students attending such schools may feel alienated and subsequently disengage from school (Feagin and Sikes 1994; Lewis 2003). Indeed, Walsemann et al. (2011) found that black students attending predominantly white junior and senior high schools reported lower levels of school attachment; they were less likely to report feeling part of their school, feeling close to people at their school, or feeling happy to be at their school. Others have found that black and Hispanic students hold more optimistic and pro-school attitudes (Goldsmith 2004) and are more connected to school (McNeely et al. 2002) when they attend predominantly minority schools. Alterna- 
tively, Asian adolescents may feel greater alienation when attending predominantly minority schools than when attending predominantly white schools. Qualitative studies in large urban schools have found that Asian youth must negotiate a complex set of social dynamics as a result of their social status within predominantly minority schools. In these studies, Vietnamese and Chinese youth were perceived of as academically superior to their black and Hispanic counterparts by their teachers, which consequently resulted in Asian youth experiencing race-related hostility and aggression from their peers (Conchas and Perez 2003; Rosenbloom and Way 2004).

Some researchers view disengagement from school as a coping strategy used by minority youth to buffer against negative stereotypes about their group (Schmader et al. 2001; Aronson 2002). However, students who report being less attached to their school report higher rates of drug use, depression, and suicide ideation (Tani et al. 2001; Bearman and Moody 2004; Bond et al. 2007). Conversely, students who feel connected to their schools are less likely to experience depressive symptoms (Walsemann et al. 2011), contemplate suicide (McNeely and Falci 2004), or engage in high-risk behaviors (Giordano 2003; McNeely and Falci 2004).

Moreover, access to key educational opportunities important for educational achievement and attainment is highly correlated with the racial composition of the school. Compared with predominantly white schools, predominantly minority schools tend to offer fewer advanced placement courses, employ less qualified teachers, and have higher student-to-teacher classroom ratios (Mickelson 2001; Darling-Hammond 2004). Predominantly minority schools also spend less per pupil, on average, than predominantly white schools (Hochschild and Scovronick 2003). This is in part due to the fact that predominantly minority schools are often concentrated in lower-income neighborhoods. Because the majority of school funding in the United States derives from local property taxes, schools in wealthier communities are able to generate more revenue for their schools and spend more per pupil than predominantly minority schools (Hochschild and Scovronick 2003). Disparate spending has a direct effect on educational achievement; research finds that school resources independently affect student achievement in math, science, reading, and history (Rumberger and Palardy 2005).

Thus, although Americans often view education as the gateway to the American Dream, US students receive unequal educations; students attending predominantly white and wealthy schools, on average, receive a better education than do students attending predominantly minority and poor schools (Hochschild and Scovronick 2003). Predominantly white schools can often provide access to educational and occupational net- works that can help their students gain admission to colleges and access to well-paying jobs. These loose networks have been shown to increase the educational attainment of black students and decrease their occupational segregation in adulthood (Wells and Crain 1994). Black and Hispanic students attending predominantly white schools may therefore experience higher socioeconomic status (SES) in adulthood as a result of gaining access to educational opportunities they may not have had access to in predominantly minority schools. Adult educational attainment is consistently associated with mental health outcomes (Aneshensel 2009); highly educated individuals are at lower risk of experiencing psychological distress (Roxburgh 2009), feelings of hopelessness (Harper et al. 2002), and depressive symptoms (Walsemann et al. 2009).

\section{Hypotheses}

We test the following four hypotheses:

Hypothesis 1 Exposure to predominantly white high schools will be associated with higher levels of depressive symptoms among blacks and Hispanics from adolescence through early adulthood.

Hypothesis 2 Given research that finds Asian adolescents experience greater discrimination within predominantly minority high schools than black or Hispanic adolescents (Conchas and Perez 2003; Rosenbloom and Way 2004), we hypothesize that, among Asians, exposure to predominantly minority high schools will be associated with higher levels of depressive symptoms from adolescence through early adulthood.

Hypothesis 3 Perceptions of discrimination and school attachment will mediate the association between high school racial composition and trajectories of depressive symptoms among blacks, Hispanics, and Asians.

Hypothesis 4 Given that social mobility may be greater among blacks and Hispanics who attended predominantly white high schools, we hypothesize that the effect of high school racial composition on black and Hispanic trajectories of depressive symptoms will be attenuated with adjustment for adult SES.

\section{Methods}

Sample

We analyzed four waves of restricted data (1994/5, $1995 / 6,2000 / 1,2007 / 8$ ) from the National Longitudinal 
Study of Adolescent Health (Add Health), a nationally representative sample of students who were enrolled in grades 7 through 12 in 1994/5 (Harris et al. 2009). The Add Health sample is representative of US schools with respect to region of country, urbanicity, school size, school type (private/public), and race/ethnicity. Our analysis utilized three data sources: (1) in-home interviews of the respondent in Waves I-IV, (2) in-home interview of the parent in Wave I, and (3) a self-administered questionnaire completed by the school administrator in Wave I.

We restricted our sample to respondents enrolled in grades 9-12 in 1994/5 who were interviewed at a minimum in Waves I and IV. This resulted in 10,653 respondents. We excluded 303 respondents who had missing data, resulting in a final analytic sample of 10,350 respondents who were enrolled in 80 high schools in 1994/5 (5,561 whites, 2,030 blacks, 1,834 Hispanics, 738 Asians, and 187 of other race). Approximately $60 \%$ of respondents provided 4 observations, $33 \%$ provided $3 \mathrm{ob}-$ servations, and $7 \%$ provided 2 observations.

\section{Measures}

\section{Dependent Variable}

We measured depressive symptoms using the nine-item Center for Epidemiological Studies Depression Scale (CES-D) available in Add Health in Waves I-IV. In each wave, respondents were asked how often each of the following things was true during the past week. They: (1) were bothered by things that usually don't bother them, (2) felt that they could not shake off the blues, even with help from family and friends, (3) felt that they were just as good as other people, (4) had trouble keeping their mind on what they were doing, (5) felt depressed, (6) felt too tired to do things, (7) enjoyed life, (8) felt sad, and (9) felt that people disliked them. Responses ranged from $0=$ never or rarely to $3=$ most of the time or all of the time. Although prior research using Add Health suggests that a reduced 5-item scale may be more applicable to studies of race and nativity (Perreira et al. 2005), we found that comparable conclusions could be made, regardless of the number of items used. Therefore, we used the nine-item scale, because only four of the five items identified in the Perreira et al. (2005) study were included in all four waves, and utilizing the nine-item scale resulted in more variability across schools and was more reliable and achieved higher criterion validity than the four-item scale. The nine-item CES-D correlates 0.96 with the 19-item CES$\mathrm{D}$ measured in Wave I, indicating high criterion validity between the nine-item CES-D and the 19-item CESD. The internal consistency (Cronbach's alpha) of the nine-item CES-D in Add Health was 0.80 in each of the four waves. Per convention, positive responses were reverse-coded and the nine items were summed. The distribution was slightly skewed; however, results using the original variable were comparable to those using a transformed variable. As a result, we chose to use the original variable in our analyses.

\section{Independent Variable - High School Racial Composition}

We measured high school racial composition as the percent of non-Hispanic white students at each high school, henceforth "percent white students." We calculated percent white students using self-reported race/ ethnicity from all students interviewed in the 1994/5 in-home survey, which we aggregated to the school level using the Wave I probability weights provided by Add Health to ensure that the aggregated data were representative of the school. We chose this specification rather than using the in-school survey which provides a full enumeration of the student body because significant measurement bias for self-reported race/ ethnicity exists in the in-school survey (Perez 2008). Values ranged from 0 to 100 . To assess the reliability of our measure, we examined the correlation between our aggregated measure and administrative data on school racial composition that was available for 69 high schools through the Common Core Data that was linked to Add Health via the Adolescent Health and Academic Achievement (AHAA) study (Muller et al. 2007); the correlation was 0.99 .

\section{Individual-Level Covariates}

Respondents self-reported their race/ethnicity, which we categorized as non-Hispanic white, non-Hispanic black, Asian/Pacific Islander, Hispanic (any race), or other. Respondents were categorized as immigrants if they reported being born outside of the United States to nonUS citizens. Gender of respondent was categorized as male or female. Age of respondent in each survey wave was used to assess change in depressive symptoms from adolescence to early adulthood.

We included a number of indicators measured at Wave I (1994/5) that may be correlated with high school racial composition or depressive symptoms. We created a measure of family structure categorized as nuclear (two biological parents), step-family (one biological and one step-parent), female-headed, extended/intergenerational family, and other. Respondents were asked how much they agreed (on a scale from 1 to 5 , where $1=$ strongly agree and $5=$ strongly disagree) that (1) "teachers at your school treat students fairly"; (2) "students are prejudiced"; (3) "you feel you are part of your school"; (4) "you feel close to people at your school"; and (5) "you are happy to be at your school". For item one, respondents were categorized as disagreed/strongly disagreed versus all else. For the remaining items, re- 
spondents were categorized as agreed/strongly agreed versus all else. We used the first two items as separate indicators of perceived discrimination and the remaining three items as separate indicators of school attachment. We constructed a composite measure of family SES because multivariate indices of SES are more reliable than single-item measures and doing so reduced issues with item-missingness. Family SES was calculated as the mean of standardized (z-score) measures of family poverty (i.e., parent-reported household income to federal poverty level in 1995), parental educational level (i.e., parent-reported 10-level ordinal variable ranging from "did not go to school" to "professional training beyond a 4-year degree"), and parental occupation (i.e., respondent-reported 7-level ordinal variable). The composite score was calculated for all respondents who had information on at least one of the indicators used in the composite measure. If the respondent resided with one parent, information for the one parent was used. If the respondent resided with two parents, the average of both parents' information was calculated. Positive values represented higher levels of family SES (Cronbach's $\alpha=0.66$ ).

Finally, we constructed a composite measure of respondents' SES at Wave IV, when respondents were 2634 years old. Adult SES was calculated as the mean of standardized ( $z$-score) measures of family poverty (i.e., respondent-reported household income to federal poverty level in 2007), respondents' educational level (i.e., respondent-reported 9-level ordinal variable ranging from "completed 8th grade or less" to "completed professional training beyond a 4-year degree"), and respondents' occupation (i.e., respondent-reported 7-level ordinal variable). The composite score was calculated for all respondents who had information on at least one of the indicators used in the composite measure. Positive values represented higher levels of adult SES (Cronbach's a $=0.63$ ).

\section{School-Level Covariates}

We included a number of school-level indicators that may be correlated with high school racial composition or depressive symptoms. We created a composite measure of school SES using the same variables included in the family SES variable, which we aggregated to the school level, to provide consistency across SES measures. School SES was calculated as the mean of standardized (z-score) measures of school-level poverty, school-level parental education, and school-level parental occupation with higher values representing higher levels of school SES (Cronbach's a = 0.90). Additional covariates included school urbanicity (urban = central city within a CMSA or MSA; suburban = CMSA or MSA with at least 2,500 residents but not in central city, rural = all else), region (west, midwest, south, and northeast), school type (public versus private), and school size (small $=1-400$ students; medium $=401-1,000$ students; large $=$ 1,001-4,000 students).

\section{Interactions}

To examine whether the effects of high school racial composition varied by respondent race/ethnicity, we included a set of interactions between high school racial composition and respondent race/ethnicity (i.e., high school racial composition $\times$ respondent race/ethnicity). To examine whether the effects of high school racial composition varied over time and whether such effects differed by respondent race/ethnicity, we modeled interactions between age $\times$ high school racial composition and age $\times$ high school racial composition $\times$ respondent race/ethnicity. Because preliminary analysis suggested that the rate of change in depressive symptoms differed by gender, we also interacted gender with age.

\section{Statistical Analysis}

We began with descriptive statistics to understand the data distribution. Three-level linear growth models were then examined to investigate the extent to which high school racial composition was associated with trajectories of depressive symptoms from adolescence to early adulthood.

First, we examined an unconditional model (not shown), with no predictors, to assess between-school variation in trajectories of depressive symptoms. All subsequent models adjusted for individual characteristics (nativity, gender, family structure at Wave I, family SES at Wave I) and high school characteristics (urbanicity, region, school type, school size, school SES). Next, we ran a model that included indicators of percent white students and percent white students by age (Model 1). We ran an additional model that included cross-level interaction terms for respondent race/ethnicity by percent white students as well as respondent race/ethnicity by percent white students by age (Model 2 ). We included indicators of perceived discrimination and school attachment in Model 3. Finally, we adjusted for respondents' SES at Wave IV (Model 4). In the model-building process, we examined changes in the -2 log likelihood to assess model fit.

The equation from our final model (Model 4) for predicting trajectories of depressive symptoms is presented below:

$$
\begin{gathered}
Y_{t i j}=\beta_{000}+\Sigma \beta_{t i j} X_{i j}+\Sigma a_{t i j} Z_{t i j}+\Sigma \lambda_{t i j} W_{j}+r_{0 i j}+r_{1 i j} \\
+\mu_{00 j}+\mu_{10 j}+\varepsilon_{t i j}
\end{gathered}
$$

where $Y_{t i j}$ is the level of depressive symptoms at time $t$ for respondent $i$ in school $j$ and assumes that conditional 
on $r_{0 i j}, r_{1 i j}, \mu_{00 j}$, and $\mu_{10 j}, Y_{t i j}$ to $Y_{t n k}$ are independent; $i$ $=1, \ldots, n$ respondents across $t=1, \ldots, T$ waves and $j=$ $1, \ldots, K$ is the number of schools included in our sample; $\beta_{000}$ is the population average depressive symptoms at age 22; $\Sigma \beta_{t i j} X_{i j}$ is the sum of time-invariant individual-level covariates (i.e., race/ethnicity, gender, immigrant status, family SES, family structure, school attachment, perceived discrimination, and respondent SES in 2007/8); $\Sigma a_{t i j} Z_{t i j}$ is the sum of time-varying individual-level covariates and cross-level interactions (i.e., age, age $\times$ gender, age $\times \%$ white students, age $\times$ race/ethnicity $\times \%$ white students); $\Sigma \lambda_{t i j} W_{j}$ is the sum of school-level covariates (i.e., \% white students, school SES, school type, region, urbanicity, and school size) and time-invariant cross-level interactions (i.e., race/ethnicity $\times \%$ white students); and $\mu_{00 j}$ and $\mu_{10 j}$ represent variation in intercepts and slope of the growth curve between schools (i.e., between-school variability) and are assumed to be randomly and normally distributed with mean zero; $r_{0 i j}$ and $r_{1 i j}$ represent the random between-person differences in the intercept and slope of the growth curve, respectively; $\varepsilon_{t i j}$ is the random within-person error at time $t$ for respondent $i$ in school $j$. Three-level linear models were specified via maximum-likelihood estimation using xtmixed in Stata (v11) (Stata Corp. 2009).

To facilitate interpretation of the intercept, age was centered at 22, the median age of respondents in the sample, high school racial composition was grand mean centered at $57 \%$, and the remaining covariates were centered at their grand means, except for race/ethnicity, gender, and nativity. Next, to help with the interpretation of the regression coefficients for high school racial composition, we transformed this variable (original variable/10) such that the reported coefficients represented a $10 \%$ increase in percent white students rather than a $1 \%$ increase in percent white students. All analyses were unweighted. As such, all models included the individual (i.e., race/ethnicity) and school (i.e., school urbanicity, school region, school type, and school size) sampling variables. By including the sampling variables, unweighted analyses produce unbiased coefficients (Winship and Radbill 1994).

\section{Sensitivity Analyses}

First, we excluded schools with 0 and $100 \%$ white students to examine our results after excluding schools at the extremes of the distribution, which may overly influence our results. The size, direction, and significance of the indicators were similar as those found in the full sample, but the sample was no longer representative of the US high school population in 1994/5. Thus, we present the findings from the full sample only. Second, we examined whether the findings were robust to specification of respondent SES by also run- ning models that included separate indicators for education, occupation, and poverty at Wave IV. These models yielded similar results, but resulted in significant loss of respondents due to missingness on occupation and poverty. Thus, we used the SES index in the models we present. Lastly, we considered interactions between age and respondent race/ethnicity; including these interactions did not improve model fit; therefore, the models we present here do not include these additional interactions.

\section{Results}

\section{Sample Characteristics}

We present sample characteristics in Table 1. The sample consisted of 10,350 respondents who were dispersed across 80 high schools (density values ranged from 8 to 1,174) and provided 36,493 person-period observations. Respondents were primarily white (53.7\%) and had slightly below-average family SES at Wave I $(M=-0.08, \min =-2.24, \max =1.43)$. There were slightly more women than men $(52.8 \%$ vs. $47.1 \%)$, the mean age over the survey interval was 22.2 years $(\min =11.9, \max =34.7)$, and $8.1 \%$ were immigrants. At Wave I, most respondents reported feeling close to people at school $(64.9 \%)$, part of their school $(70.2 \%)$, and happy to be at school (64.8\%), whereas $21.3 \%$ of respondents reported that teachers treated students unfairly and $46.9 \%$ reported that students at their school were prejudiced. On average, most respondents attended high schools in 1994/5 that were large (63.3\%), suburban $(54.1 \%)$, public $(92.9 \%)$, and primarily white $(56.9 \%)$ in their student body composition and had slightly above-average SES $(M=0.14, \min =-1.80$, $\max$ $=2.15$ ). At Wave IV, respondents on average reported slightly below-average SES $(M=-0.01, \mathrm{~min}=-2.40$, $\max =1.33$ ).

Significant bivariate racial/ethnic differences in level of depressive symptoms were noted. We also found bivariate racial/ethnic differences across all covariates with the exception of respondents' age. For example, at Wave I, whites lived in families with slightly above-average SES (0.11); however, blacks, Hispanics, and Asian/ Pacific Islanders lived in families with slightly belowaverage SES $(-0.17,-0.55$, and -0.07 , respectively). Approximately $21.7 \%$ of whites reported unfair treatment by teachers, whereas $25.7 \%$ of blacks, $17.2 \%$ of Hispanics, and $13.6 \%$ of Asian/Pacific Islanders did so. At Wave IV, whites and Asian/Pacific Islanders reported slightly above-average SES (0.02 and 0.12, respectively), but blacks and Hispanics reported slightly below-average SES (-0.13 and -0.10 , respectively). Consistent with national estimates of school segregation (Orfield and Lee 2007), white respondents attended high schools where 


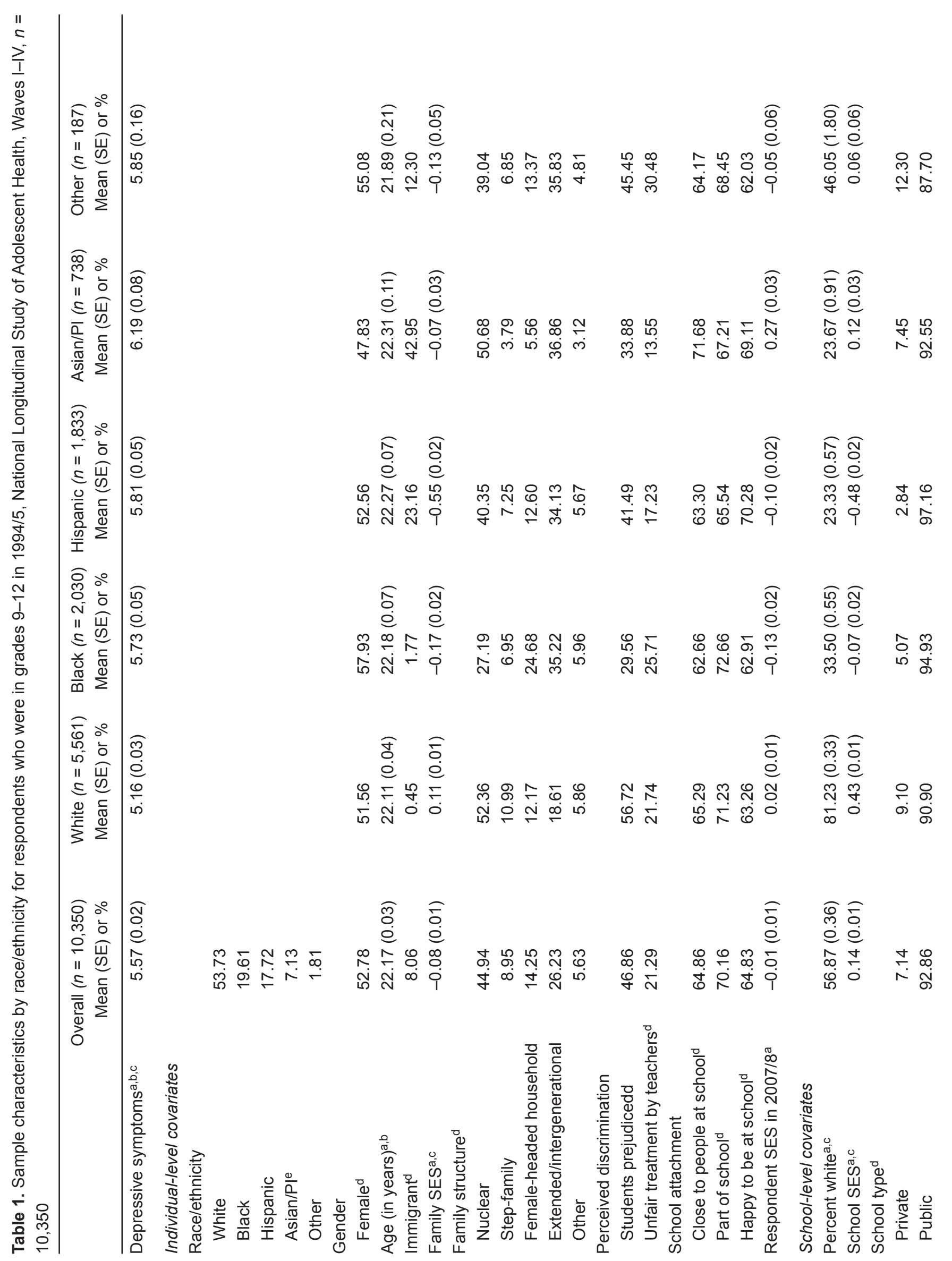




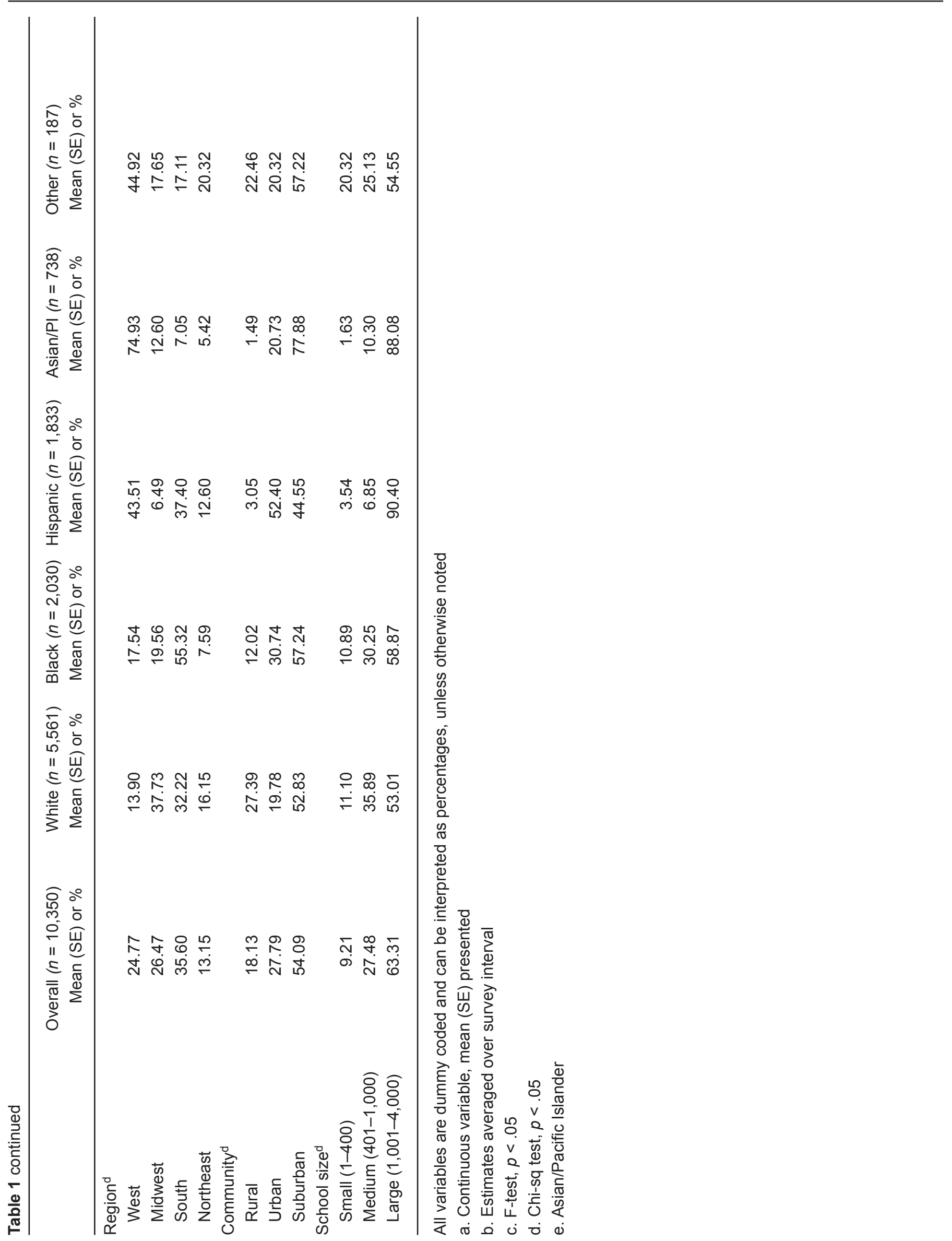


Table 2. Estimates from three-level linear growth models predicting depressive symptoms from adolescence to early adulthood for respondents in grades 9-12 in 1994/5, National Longitudinal Study of Adolescent Health, Waves I-IV, $n=10,350$

\begin{tabular}{|c|c|c|c|c|}
\hline & $\begin{array}{c}\text { Model } 1 \\
b(\mathrm{SE})\end{array}$ & $\begin{array}{c}\text { Model } 2 \\
b(\mathrm{SE})\end{array}$ & $\begin{array}{c}\text { Model } 3 \\
b(\mathrm{SE})\end{array}$ & $\begin{array}{c}\text { Model } 4 \\
b(\mathrm{SE})\end{array}$ \\
\hline Intercept & $4.822(0.070)^{\star * *}$ & $4.893(0.079)^{* * *}$ & 4.SS0 $(0.075)^{* * *}$ & $4.693(0.074)^{* * *}$ \\
\hline \multicolumn{5}{|l|}{ Level-I variables } \\
\hline $\mathrm{Age}^{\mathrm{a}}$ & $-0.051(0.005)^{* * *}$ & $-0.044(0.007)^{\star \star *}$ & $-0.044(0.007)^{\star * *}$ & $-0.044(0.007)^{* * *}$ \\
\hline \multicolumn{5}{|l|}{ Level-2 variables } \\
\hline \multicolumn{5}{|l|}{ Race/ethnicity (ref = white) } \\
\hline Black & $0.236(0.103)^{*}$ & $0.330(0.110)^{* *}$ & $0.328(0.107)^{\star *}$ & $0.259(0.105)^{*}$ \\
\hline Hispanic & $0.152(0.115)$ & $0.086(0.130)$ & $0.149(0.125)$ & $0.135(0.123)$ \\
\hline Asian/PI & $0.893(0.152)^{* * *}$ & $0.456(0.203)^{*}$ & $0.504(0.196)^{\star *}$ & $0.776(0.192)^{* * *}$ \\
\hline Other & $0.337(0.230)$ & $0.332(0.242)$ & $0.259(0.233)$ & $0.265(0.228)$ \\
\hline Female & $0.981(0.059)^{* * *}$ & $0.980(0.059)^{* * *}$ & $0.924(0.057)^{* * *}$ & $1.178(0.057)^{* * *}$ \\
\hline \multicolumn{5}{|l|}{ Perceived discrimination } \\
\hline Unfair treatment by teachers & & & $0.711(0.073)^{\star \star \star}$ & $0.651(0.071)^{* *}$ \\
\hline Students prejudiced & & & $0.200(0.060)^{* * *}$ & $0.241(0.059)^{* * *}$ \\
\hline \multicolumn{5}{|l|}{ School attachment } \\
\hline Close to people at school & & & $-0.344(0.069)^{\star * *}$ & $-0.319(0.067)^{* * *}$ \\
\hline Part of school & & & $-0.811(0.074)^{\star * *}$ & $-0.710(0.072)^{\star * *}$ \\
\hline Happy to be at school & & & $-0.592(0.069)^{\star \star *}$ & $-0.541(0.068)^{* * *}$ \\
\hline Respondent SES in Wave IV & & & & $-0.881(0.041)^{\star * *}$ \\
\hline \multicolumn{5}{|l|}{ Level-3 variables } \\
\hline$\%$ white ${ }^{c}$ & $0.005(0.020)$ & $-0.032(0.026)$ & $-0.027(0.025)$ & $-0.042(0.024)$ \\
\hline \multicolumn{5}{|l|}{ Cross-level interactions } \\
\hline Age $\times$ female & $-0.047(0.007)^{* * *}$ & $-0.048(0.007)^{\star * *}$ & $-0.049(0.007)^{* * *}$ & $-0.048(0.007)^{\star * *}$ \\
\hline Age $\times \%$ white & $0.004(0.002)^{* * *}$ & $0.001(0.002)$ & $0.001(0.002)$ & $0.001(0.002)$ \\
\hline Black $\times \%$ white & & $0.108(0.035)^{\star \star}$ & $0.074(0.033)^{*}$ & $0.056(0.033)$ \\
\hline Hispanic $\times \%$ white & & $0.021(0.036)$ & $0.003(0.035)$ & $-0.029(0.034)$ \\
\hline Asian/PI $\times \%$ white & & $-0.088(0.051)$ & $-0.116(0.049)^{*}$ & $-0.109(0.048)^{*}$ \\
\hline Other $\times \%$ white & & $0.086(0.073)$ & $0.063(0.070)$ & $0.047(0.068)$ \\
\hline Age $\times$ black $\times \%$ white & & $-0.003(0.004)$ & $-0.002(0.003)$ & $-0.002(0.004)$ \\
\hline Age $\times$ Hispanic $\times \%$ white & & $0.013(0.004)^{\star * *}$ & $0.013(0.004)^{* * *}$ & $0.013(0.004)^{* * *}$ \\
\hline Age $\times$ Asian $/ \mathrm{PI} \times \%$ white & & $0.014(0.004)^{\star *}$ & $0.014(0.005)^{* *}$ & $0.014(0.005)^{* *}$ \\
\hline Age $\times$ other $\times \%$ white & & $0.005(0.008)$ & $0.005(0.008)$ & $0.008(0.008)$ \\
\hline \multicolumn{5}{|l|}{ Random effects } \\
\hline$\mu_{00 j}$ & 0.26 & 0.24 & 0.21 & 0.20 \\
\hline$\mu_{10 j}$ & 0.04 & 0.03 & 0.03 & 0.03 \\
\hline$r_{0 i j}$ & 2.46 & 2.45 & 2.32 & 2.25 \\
\hline$r_{1 i j}$ & 0.17 & 0.17 & 0.17 & 0.17 \\
\hline$\Delta-2$ Log likelihood ${ }^{d}$ & $-772.26^{* * *}$ & $-46.90^{* * *}$ & $-742.52^{\star * *}$ & $-442.68^{* * *}$ \\
\hline
\end{tabular}

Unconditional model variance estimates: $\mu_{00 j}=0.50, \mu_{10 j}=0.08, r_{0 i j}=-2.56$, and $r_{1 i j}=0.17$.

All models adjusted for nativity, and at Wave I, family structure, family SES, urbanicity, school type, school size, region, and school SES.

All covariates centered at their grand means, except for gender, race/ethnicity, and nativity.

a. Age is centered at 22

b. Asian/Pacific Islander

c. Percent white students centered at $57 \%$ and divided by 10

d. Change in the -2LL contrasts Model 1 to an unconditional model (not shown), Model 2 to Model I, Model 3 to Model 2, and Model 4 to

Model 3.

${ }^{*} p<0.05 ;{ }^{* *} p<0.01 ;{ }^{* * *} p<0.001$ 


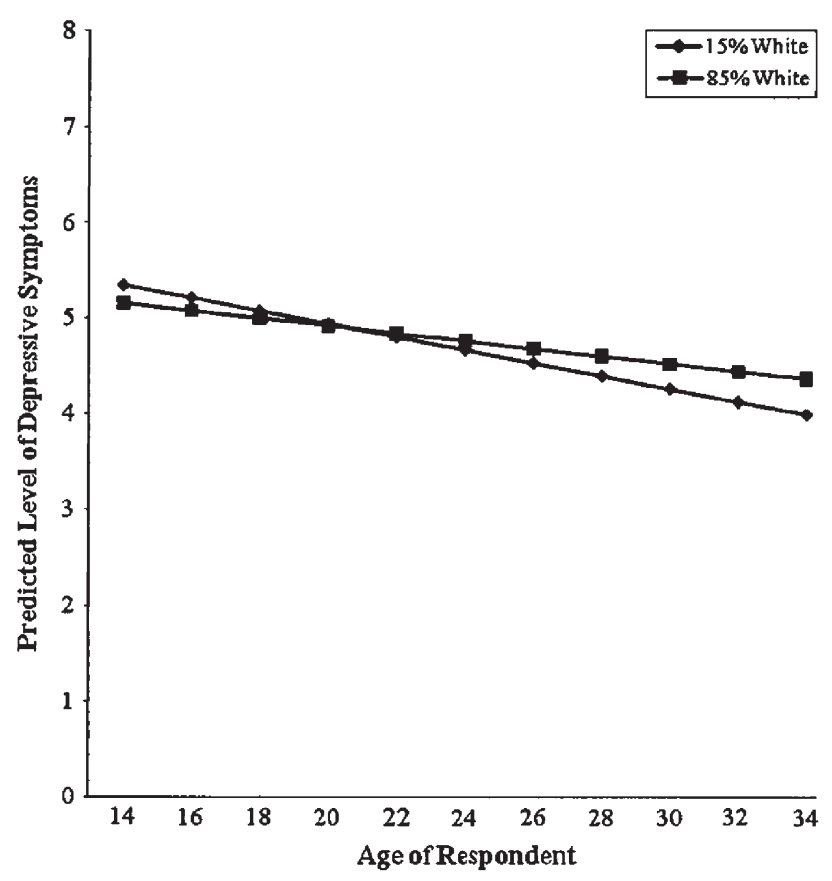

Figure 1. Predicted level of depressive symptoms from adolescence through early adulthood for male respondents, national longitudinal study of adolescent health, Waves I-IV. Predicted trajectories based on Model I estimates and are conditional on $r_{0 i j}, r_{1 i j}, \mu_{00 j}$, and $\mu_{10 j}=0$. Predicted trajectories by percent white are statistically different at $p<.05$

most students were white $(81.2 \%)$, whereas black, Hispanic, and Asian/Pacific Islander respondents attended high schools with notably lower proportions of white students (33.5, 23.3, and $23.7 \%$, respectively).

\section{Three-Level Linear Growth Models}

We first examined the effect of high school racial composition on trajectories of depressive symptoms in Table
2. Results from Model 1, the least restrictive model, revealed a statistically significant interaction between age and percent white students $(b=0.004, p<0.001)$; however, the main effect of percent white students was nonsignificant $(b=0.005, p>0.05)$. For illustration, we plot predicted trajectories of depressive symptoms for two values of percent white students (i.e., 15 and 85\%) in Figure 1. For ease of presentation, we only plot trajectories for male respondents; however, it is important to note that the effect of high school racial composition did not vary by gender. On average, respondents who attended predominantly white high schools (i.e., $85 \%$ white students) had lower levels of depressive symptoms at age 14 than respondents who attended predominantly minority high schools (i.e., 15\% white students). By age 34, this pattern was reversed, revealing a slightly faster decline in depressive symptoms among respondents who attended predominantly minority high schools.

Next, we tested our hypotheses that attending predominantly white high schools would be associated with higher levels of depressive symptoms among blacks and Hispanics, but lower levels of depressive symptoms among Asian/Pacific Islanders, from adolescence through early adulthood. After inclusion of twoway (percent white students $\times$ respondent race/ethnicity) and three-way interactions (age $\times$ percent white students $\times$ respondent race/ethnicity ) in Model 2, the interaction between age and percent white students was attenuated $(b=0.001, p>0.05)$. However, interactions between percent white students and respondent race/ ethnicity indicated that as the percentage of white students at school increased, black respondents reported higher levels of depressive symptoms $(b=0.108, p<$ $0.01)$. This effect did not differ over time $(b=-0.003, p$ $>0.05$ ). However, the effect of percent white students on depressive symptoms for Hispanic and Asian/Pacific Islander respondents differed by age. For example,
Figure 2. Predicted level of depressive symptoms from adolescence through early adulthood for male respondents by percent white students in high school and race/ethnicity, National Longitudinal Study of Adolescent Health, Waves I-IV. Predicted trajectories for $\mathbf{a} \& \mathbf{b}$ are based on Model 2 estimates and are conditional on $r_{0 i j}, r_{1 i j}, \mu_{00 j}$, and $\mu_{10 j}=0$. The trajectories for Asian/PI, Hispanics, and blacks differ by percent white students at their high schools.
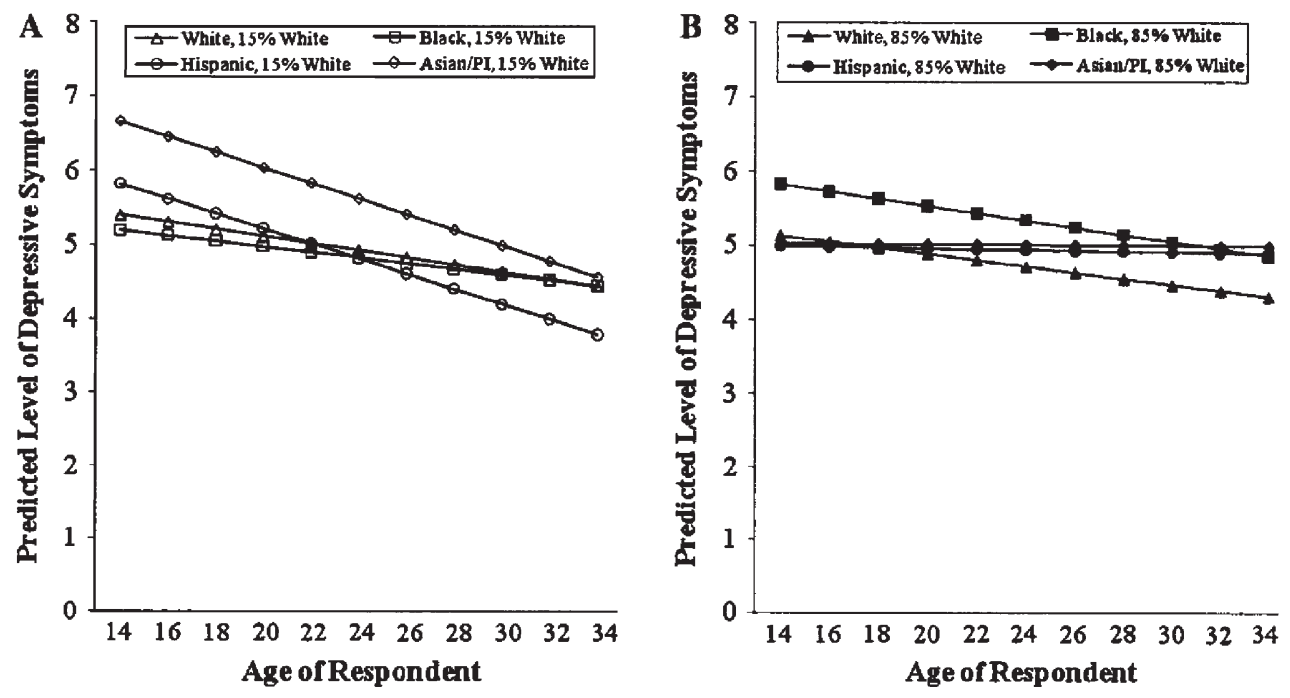
male Asian/Pacific Islanders attending schools with $15 \%$ white students reported, on average, 6.7 depressive symptoms at age 14 and 4.6 depressive symptoms at age 34--a decline of 2.1 depressive symptoms from adolescence to early adulthood (see Figure 2a). In comparison, male Asian/Pacific Islanders attending schools with $85 \%$ white students reported, on average, 5.03 depressive symptoms at age 14 and 4.99 depressive symptoms at age 34--a decline of 0.04 depressive symptoms (see Figure 2b). Thus, Asian/Pacific Islanders attending predominantly minority high schools had higher levels of depressive symptoms in adolescence than their counterparts attending predominantly white high schools, but they also experienced a faster decline in depressive symptoms. This pattern was also found among Hispanic respondents.

Figures $2 \mathrm{a}$ and $2 \mathrm{~b}$ also illustrate important racial/ ethnic differences in trajectories of depressive symptoms across levels of percent white students at school. That is, in predominantly minority high schools, black respondents reported the lowest levels of depressive symptoms at age 14; Asian/Pacific Islanders reported the highest levels of depressive symptoms, with whites and Hispanics falling in-between. However, by age 34, whites, Asian/Pacific Islanders, and blacks reported similar levels of depressive symptoms; Hispanics reported the lowest levels of depressive symptoms. In comparison, in predominantly white high schools, blacks reported the highest levels of depressive symptoms at age 14, whereas Asian/Pacific Islanders, Hispanics, and whites reported similar levels of depressive symptoms. By age 34, whites reported the lowest levels of depressive symptoms, with blacks, Hispanics, and Asian/Pacific Islanders reporting similar levels of depressive symptoms.

To test our hypothesis that perceptions of discrimination and school attachment would mediate the association between high school racial composition and trajectories of depressive symptoms among blacks, Hispanics, and Asian/Pacific Islanders, we adjusted for measures of perceived discrimination and school attachment in Model 3. Each of these individual indicators were significantly associated $(p<0.001)$ with depressive symptoms; respondents who indicated that teachers treated students unfairly and that students were prejudiced experienced higher levels of depressive symptoms ( $b$ $=0.711, b=0.200$, respectively), whereas respondents who reported feeling close to people at school, part of their school, and happy to be at their school experienced lower levels of depressive symptoms $(-0.344,-0.811$, and -0.592 , respectively). Inclusion of these measures slightly attenuated the size of the effect of high school racial composition on trajectories of depressive symptoms for black respondents $(b=0.108, p<0.01$ in Model 2 versus $b=0.074, p<0.05$ in Model 3), but did not attenuate the effect for Hispanics or Asian/Pacific Islanders.
Finally, we tested our hypothesis that the effect of high school racial composition on trajectories of depressive symptoms among blacks and Hispanics would be attenuated with adjustment for adult SES (Model 4). Adult SES was inversely associated with depressive symptoms; higher SES respondents experienced lower levels of depressive symptoms. Adjustment for adult SES further attenuated the effect of percent white students for black respondents $(b=0.056, p>0.05)$, but did not attenuate the effect of percent white students on trajectories of depressive symptoms for Hispanics or Asian/Pacific Islanders.

\section{Discussion}

Our analysis of high school racial composition and trajectories of depressive symptoms indicates four major findings. First, as hypothesized, black respondents who attended predominantly white high schools reported higher levels of depressive symptoms than black respondents who attended predominantly minority high schools. This effect was constant from adolescence through early adulthood. Second, as hypothesized, Asian/Pacific Islanders reported higher levels of depressive symptoms during adolescence if they attended predominantly minority high schools rather than predominantly white high schools. Unexpectedly, this effect dissipated with age, such that by age 30, depressive symptoms were similar for Asian/Pacific Islanders regardless of the racial composition of their high school. Also contrary to our hypothesis, the effect of high school racial composition on trajectories of depressive symptoms among Hispanics was comparable to the effect found for Asian/Pacific Islanders rather than the effect found for blacks. Third, perceived discrimination and school attachment appeared to mediate the relationship between high school racial composition and trajectories of depressive symptoms, but only for black respondents. Fourth, adult SES attenuated the effect of high school racial composition on trajectories of depressive symptoms among black but not among Hispanic respondents.

Our results for black respondents suggest that the high school environment may help to establish racial disparities in trajectories of depressive symptoms and that ignoring adolescent social environments may result in the mistaken conclusion that black adolescents and young adults uniformly experience higher levels of depressive symptoms compared with whites during this developmental period. Indeed, our results show that blacks who attended predominantly minority high schools had similar or lower levels of depressive symptoms than whites, whereas the reverse was true for blacks who attended predominantly white high schools. According to life course theory, certain 
social environments have a more profound effect on health when they are experienced during specific developmental stages (Kuh et al. 2003). Outside of this period, the effect is much weaker. Given that the development of psychological problems in adolescence increases the risk of recurrent psychological problems in adulthood (George 2007; Pine et al. 1999), this sensitive period effect may in part explain our results for black respondents.

Although a significant body of cross-sectional research finds that discrimination is associated with mental health (Williams et al. 2003), we find that discrimination experienced during adolescence continues to impact mental health years later. Our finding that perceived discrimination and school attachment partly mediated the relationship between high school racial composition and depressive symptoms among blacks is consistent with prior research that finds that black students often feel alienated and isolated when attending predominantly white schools (Feagin et al. 1996; Lewis 2003; Walsemann et al. 2011) and that feelings of alienation and isolation increase the risk of psychological problems (Heinrich and Gullone 2006). However, in models adjusting for adult SES, the effect of high school racial composition on depressive symptoms among blacks was attenuated. It is possible that the negative psychological consequences of experiencing discrimination within predominantly white high schools is diminished or reversed by the greater social mobility of these same students. Such interpretation corresponds to the idea that sensitive period effects are modifiable and potentially reversible (Kuh et al. 2003).

Unlike blacks, Asian/Pacific Islanders experienced higher levels of depressive symptoms in adolescence if they attended a predominantly minority high school; this effect dissipated over time. Asian American youth occupy a unique status as a marginalized minority. Within ethnically diverse high schools, Asian American adolescents are at higher risk of experiencing discrimination, being racially insulated, and being socially excluded relative to their black and Hispanic peers (Conchas and Perez 2003; Rosenbloom and Way 2004). There is evidence that as early as sixth grade, Asian American youth begin experiencing greater amounts of race-related discrimination and as a result report elevated levels of depressive symptoms (Rivas-Drake et al. 2008). Although we adjusted for measures of perceived discrimination, these items may not have fully captured the extent of discrimination experienced by Asian/Pacific Islanders attending predominantly minority high schools in our sample. For example, Asian American youth and young adults also experience the perception of being a "perpetual foreigner" who pose a threat economically or educationally (Tuan 1998; Alvarez et al. 2006). Future research should consider the negative consequences of not only racially motivated discrimination but also anti-immigrant hostility that may increase feelings of social exclusion.

Contrary to our expectations, the relationship between high school racial composition and trajectories of depressive symptoms among Hispanics was similar to the relationship found among Asian/Pacific Islanders. Although Hispanics experience significant discrimination in predominantly white educational settings (McCabe 2009), there may be other mechanisms at play within predominantly minority high schools. Post hoc analyses revealed that Hispanics in our sample who attended predominantly minority high schools were more likely to be immigrants and speak a foreign language, compared with Hispanics who attended predominantly white high schools. Hispanic students designated as English learners (ELs) are often assigned to special education courses, which can hinder their educational achievement and social integration within the school (Gándara et al. 2003). A second explanation might lie with family support and identity formation during adolescence and early adulthood (Landale et al. 2006; Portes and Rumbaut 2006). Children of immigrants often face challenges related to their identity search during youth, as well as conflicts with their parents, which can be exacerbated by competing cultural differences between immigrants and the dominant culture. Such conflict may increase psychological problems in adolescence, but as youth age, these issues may dissipate. This may also be the case for Asian/Pacific Islanders.

Moreover, significant ethnic heterogeneity exists within the Hispanic and Asian/Pacific Islander populations. Although we adjusted for family SES, school SES, and nativity, the results for both Hispanic and Asian/ Pacific Islanders could be driven by unmeasured heterogeneity coupled with less dispersion of Hispanics and Asian/Pacific Islanders across high schools in our sample. Although Hispanic and Asian/Pacific Islander subgroups in our sample generally attended racially mixed high schools, some subgroups attended schools with greater percentages of white students (results not shown). Additionally, regional and state-level variation in educational settings may be affecting our results. There were significant concentrations of particular ethnic groups within regions in our sample; for example, $97 \%$ of Filipinos and $69 \%$ of Mexicans attended high schools in the western region of the United States. Though we adjusted for regional differences, significant variation in educational curriculum, classroom size, funding, and immigration policy exists across states, which are likely not captured with our measure of region. Additional studies that not only include a larger number of Hispanics and Asian/Pacific Islanders but also sample a larger number of schools are needed to provide a more complete picture of the effect of school environments on the mental health of Hispanics and Asian/Pacific Islanders. 


\section{Limitations}

First, our sample includes individuals who were enrolled in senior high schools in the United States in 1994/5; thus, we can only generalize to this population. However, to our knowledge, Add Health is the only longitudinal, nationally representative school-based survey in the United States that allows for the analysis of school-level associations with trajectories of depressive symptoms through early adulthood. Second, depressive symptoms constitute only one dimension of mental health. Other mental health outcomes such as anxiety, psychological distress, and clinical depression should be explored in future research. Finally, although adolescents and young adults navigate many social settings on a daily basis, our analyses and results are limited to the high school environment. Other social environments, including college campuses and neighborhoods, also affect the psychological well-being of adolescents and young adults (Aneshensel and Sucoff 1996; Feagin et al. 1996; Leventhal and Brooks-Gunn 2003). We chose to limit our analyses to high schools given that schools are one of the strongest socializing forces during adolescence (Hallinan 2001) and adolescence is a critical period for the establishment of psychological problems across the life course (George 2007). Additional research is needed to understand how different social settings across key developmental periods interact to affect mental health across the life course.

\section{Conclusions}

Our study provides preliminary evidence that school settings matter for mental health not only during adolescence but also in early adulthood. The transition from adolescence to adulthood can often be challenging, but the transition may be even more arduous for those youth who experienced discrimination and alienation within their high schools. Yet, our results also suggest that the effects of exposure to disadvantage during sensitive developmental periods on mental health may be reversed. Under what conditions and through what mechanisms reversal occurs is an important next step in understanding how racial disparities in mental health vary across the life course.

Acknowledgments - This research was supported by the University of Michigan's Robert Wood Johnson Foundation Health \& Society Scholars Program (grant N008885). This research used data from the National Longitudinal Study of Adolescent Health, a program project by Kathleen Mullan Harris, designed by J. Richard Udry, Peter S. Bearman, and Kathleen Mullan Harris at the University of North Carolina at Chapel Hill, and funded by grant P01-HD31921 from the Eunice Kennedy Shriver National Institute of Child Health and Human Development, with cooperative funding from 23 other federal agencies and foundations. Special acknowledgment is due to Ronald R. Rindfuss and Barbara Entwisle for assistance in the original 143 design. Information on how to obtain the Add Health data files is available on the Add Health website (http://www.cpc.unc.edu/addhealth ). This research also used data from the Adolescent Health and Academic Achievement study, which was funded by a grant (R01 HD040428-02, Chandra Muller, PI) from the National Institute of Child Health and Human Development, and a grant (REC0126167, Chandra Muller, PI, and Pedro Reyes, Co-PI) from the National Science Foundation. This research was also supported by grant 5 R24 HD042849, Population Research Center, awarded to the Population Research Center at the University of Texas at Austin by the Eunice Kennedy Shriver National Institute of Health and Child Development. No direct support was received from grants P01-HD31921, R01 HD040428-02, or 5 R24 HD042849 for this analysis.

\section{References}

Adkins, D. E., Wang, V., Dupre, M. E., van den Oord, E. J., \& Elder, G. H., Jr. (2009). Structure and stress: Trajectories of depressive symptoms across adolescence and young adulthood. Social Forces, 88, 31-60.

Alvarez, A., Juang, L., \& Liang, C. (2006). Asian Americans and racism: When bad things happen to "model minorities". Cultural Diversity and Ethnic Minority Psychology, 12, 477-492.

Aneshensel, C. S. (2009). Toward explaining mental health disparities. Journal of Health and Social Behavior, 50, 377-394.

Aneshensel, C. S., \& Sucoff, C. A. (1996). The neighborhood context of adolescent mental health. Journal of Health and Social Behavior, 37, 293-310.

Aronson, J. (2002). Stereotype threat: Contending and coping with unnerving expectations. In J. Aronson (ed.), Improving academic achievement: Impact of psychological factors on education (pp. 279-301). San Diego, CA: Academic Press.

Avison, W. R. (2010). Incorporating children's lives into a life course perspective on stress and mental health. Journal of Health and Social Behavior, 51, 361-375.

Bearman, P. S., \& Moody, J. (2004). Suicide and friendships among American adolescents. American Journal of Public Health, 94, 89-95.

Bond, L., Bulter, H., Thomas, L., Carlin, J., et al. (2007). Social and school connectedness in early secondary school as predictors of late teenage substance use, mental health, and academic outcomes. Journal of Adolescent Health. 40, 357.e9357.e18.

Botticello, A. (2009). School contextual influences on the risk for adolescent alcohol misuse. American Journal of Community Psychology, 43, 85-97.

Bourdieu, P. (1973). Cultural reproduction and social reproduction. In R. Brown (ed.), Knowledge, education, and cultural change (pp. 71-112). London: Tavistock Publications Limited.

Conchas, G., \& Perez, C. (2003). Surfing the "model minority" wave of success: How the school context shapes distinct experiences among Vietnamese youth. New Directions for Youth Development, 100, 41-56. 
Darling-Hammond, L. (2004). Inequality and the right to learn: Access to qualified teachers in California's public schools. Teachers College Record. 106, 1936-1966.

Elder. G. H., Kirkpatrick Johnson, M., \& Crosnoe, R. (2003). The emergence and development of life course theory. In J. Mortimer \& M. I. Shanahan (eds.), Handbook of the life course (pp. 3-19). New York: Springer.

Feagin. J. R.. \& Sikes, M. P. (1994). Living with racism: The black middle-class experience. Boston: Beacon Press.

Feagin, J. R, Vera, H., \& Imani, N. (1996). The agony of education. New York: Routledge.

Gándara, P., Rumberger, R., Maxwell-Jolly, J., \& Callahan, R. (2003). English learners in California schools: Unequal resources, unequal outcomes. Education Policy Analysis Archives, 11(36). Retrieved April 27, 2011, from http://epaa. asu.edu/epaa/v11n36/

George, L. (2007). Life course perspectives on social factors and mental illness. In W. R. Avison, J. D. McLeod \& B. A. Pescosolido (eds.), Mental health, social mirror (pp. 191-218). Springer, US.

Giordano, P. (2003). Relationships in adolescence. Annual Review of Sociology, 29, 257-281.

Goldsmith, P. A. (2004). Schools' racial mix, students' optimism, and the black-white and Latino-white achievement gaps. Sociology of Education, 77, 121-147.

Hallinan, M. T. (2001). Sociological perspectives on blackwhite inequalities in American schooling. Sociology of Education, 74, 50-70.

Harper, S., Lynch, 1., Hsu, W.-L., Everson, S. A., Hillemeier, M. M., Raghunathan, T. E., et al. (2002). Life course socioeconomic conditions and adult psychosocial functioning. International Journal of Epidemiology, 31, 395-403.

Harris, K. M., Halpern C. T., Whitsel E., Hussey, J., Tabor, J., Entzel, P., \& Udry, J. R (2009). The National Longitudinal Study of Adolescent Health: Research Design. Retrieved April 27, 2011 from http://www.cpc.unc.edu/projects/ addhealth/design

Heinrich, L. M., \& Gullone, E. (2006). The clinical significance of loneliness: A literature review. Clinical Psychology Review, 26, 695-718.

Hochschild, J., \& Scovronick, N. (2003). The American dream and the public schools. New York: Oxford University Press.

Johnson, R A., \& Hoffmann, 1. P. (2000). Adolescent cigarette smoking in US racial/ethnic subgroups: Findings from the national education longitudinal study. Journal of Health and Social Behavior, 41, 392-407.

Juang, L., \& Cookston, J. T. (2009). Acculturation, discrimination, and depressive symptoms among Chinese American adolescents: A longitudinal study. Journal of Primary Prevention, 30, 475-496.

Kessler, R, Davis, C., \& Kendler, K. (1997). Childhood adversity and adult psychiatric disorder in the US. Psychological Medicine, 27, 1101-1119.

Kuh, D., Ben-Shlomo, Y., Lynch, 1., Hallqvist, J., \& Power, C. (2003). Life course epidemiology. Journal of Epidemiology and Community Health, 57, 778-783.

Landale, N. S., Oropesa, R S., \& Bradatan, C. (2006). Hispanic families in the United States: Family structure and process in an era of family change. In M. Tienda \&
F. Mitchell (eds.), Hispanics and the future of America (pp. 138-178). Washington, DC: The National Academies Press.

Leventhal, T., \& Brooks-Gunn, J. (2003). Moving to opportunity: An experimental study of neighborhood effects on mental health. American Journal of Public Health, 93, 1576-1582.

Lewis, A. E. (2003). Race in the schoolyard: Negotiating the color line in classrooms and communities. Piscataway, NJ: Rutgers University Press.

McCabe, J. (2009). Racial and gender micro-aggressions on a predominantly-white campus: Experiences of Black, Latino/a, and White undergraduates. Race, Gender, \& Class, 16, 133-151.

McNeely, C. A., \& Falci, C. (2004). School connectedness and the transition into and out of health-risk behavior among adolescents: A comparison of social belonging and teacher support. Journal of School Health, 74, 284--292.

McNeely, C. A., Nonnemaker, J. M., \& Blum, R. W. (2002). Promoting school connectedness: Evidence from the national longitudinal study of adolescent health. Journal of School Health, 72, 138-146.

Mickelson, R A. (2001). Subverting Swann: First- and second-generation segregation in the Charlotte-Mecklenburg Schools. American Educational Research Journal, 38, 215-252.

Mickelson, R. A., \& Everett, B. J. (2008). Neotracking in North Carolina: How high school courses of study reproduce race and class-based stratification. Teachers College Record, 110, 535-570.

Muller, C., Pearson, J., Riegle-Crumb C., Requejo, J. H., Frank, K. A., Schiller, K. S., et al. (2007). National longitudinal study of adolescent health: Wave III data: Design and implementation of the adolescent health and academic achievement study. Retrieved April 27, 2011 from http://www.laits.utexas.edu/ ahaa/docs/StudyDesign_2007.pdf

Oakes, J., Wells, A. S., Jones, M., \& Datnow, A. (1997). Detracking: The social construction of ability, cultural politics, and resistance to reform. Teachers College Record, 98, 482-510.

Orfield, G., \& Lee, C. (2007). Historic reversals, accelerating resegregation, and the need for new integration strategies. A report of the civil rights project. Retrieved April 27, 2011 from http:// www.civilrightsproject.ucla.edu/research/deseg/reversals_reseg_need.pdf

Pavalko, E. K., Mossakowski, K. N., \& Hamilton, V. J. (2003). Does perceived discrimination affect health? Longitudinal relationships between work discrimination and women's physical and emotional health. Journal of Health and Social Behavior, 44, 18-33.

Perez, A. D. (2008). Who is Hispanic? Shades of ethnicity among Latino/a youth. In C. Gallagher (ed.), Racism in postrace America: New theories, new directions (pp. 17-35). Chapel Hill, NC: Social Forces.

Perreira, K. M., Deeb-Sossa, N., Mullan Harris, K., \& Bollen, K. (2005). What are we measuring? An evaluation of the CES$\mathrm{D}$ across race/ethnicity and immigrant generation. Social Forces, 83(4), 1567-1602.

Pickett, K. E., \& Wilkinson, R G. (2008). People like us: Ethnic group density effects on health. Ethnicity and Health, 13, 321-334. 
Pine, D. S., Cohen, E., Cohen, P., \& Brook, J. (1999). Adolescent depressive symptoms as predictors of adult depression: Moodiness or mood disorder? American Journal of Psychiatry, 156, 133-135.

Portes, A., \& Rumbaut, R. G. (2006). Immigrant America: A portrait (3rd ed.). Berkeley, CA: University of California Press.

Rivas-Drake, D., Hughes, D., \& Way, N. (2008). A closer look at peer discrimination, ethnic identity, and psychological well-being among urban Chinese American sixth graders. Journal of Youth and Adolescence, 37, 12-21.

Roeser, R W., Eccles, J. S., \& Sameroff, A. J. (2000). School as a context of early adolescents' academic and social-emotional development: A summary of research findings. The Elementary School Journal, 100, 443-471.

Rosenbloom, S. R., \& Way, N. (2004). Experiences of discrimination among African American, Asian American, and Latino adolescents in an urban high school. Youth and Society, $35,420-451$.

Roxburgh, S. (2009). Untangling inequalities: Gender, race, and socioeconomic differences in depression. Sociological Forum, 24, 357-381.

Rubin, B. (2008). Detracking in context: How local constructions of ability complicate equity-geared reform. Teachers College Record, 110, 646-699.

Rumberger, R. W., \& Palardy, G. J. (2005). Does segregation still matter? The impact of student composition on academic achievement in high school. Teachers College Record, 107, 1999-2045.

Schmader, T., Major, B., \& Gramzow, R. H. (2001). Coping with ethnic stereotypes in the academic domain: Perceived injustice and psychological disengagement. Journal of Social Issues. 57, 93-111.

Schulz, A. J., Gravlee. C. C., Williams. D. R., Israel, B. A., Mentz, G., \& Rowe, Z. (2006). Discrimination, symptoms of depression, and self-rated health among African American women in Detroit: Results from a longitudinal analysis. American Journal of Public Health, 96, 1265-1270.

Stata Corp. (2009). Stata statistical software. Release 10.0. TX: College Station.
Swartz, D. (1997). Culture \& power: The sociology of Pierre Bourdieu. Chicago: The University of Chicago Press.

Tani, C. R., Chavez, E. L., \& Deffenbacher, J. L. (2001). Peer isolation and drug use among white and non-hispanic white and Mexican American adolescents. Adolescence, 36(141), 127-139.

Thoits, P. A. (2010). Stress and health: Major findings and policy implications. Journal of Health and Social Behavior, 51, S41- S53.

Tuan, M. (1998). Forever foreigners or honorary whites? New Brunswick. NJ: Routledge Press.

Walsemann, K. M., \& Bell, B. A. (2010). Integrated schools, segregated curriculum: Effects of within-school segregation on adolescent health behaviors and educational aspirations. American Journal of Public Health, 100, 1687-1695.

Walsemann, K. M., Gee, G. C., \& Geronimus, A. T. (2009). Ethnic differences in trajectories of depressive symptoms: Disadvantage in family background, high school experiences, and adult characteristics. Journal of Health and Social Behavior, 50, 82-98.

Walsemann, K. M., Bell, B. A., \& Maitra, D. (2011). The intersection of school racial composition and student race/ethnicity on adolescent depressive and somatic symptoms. Social Science and Medicine, 72, 1873-1883.

Wells, A. S., \& Crain, R. L. (1994). Perpetuation theory and the long-term effects of school desegregation. Review of Educational Research, 64, 531-555.

Williams, D., Neighbors, H. W., \& Jackson, J. S. (2003). Racial/ ethnic discrimination in health: Findings from community surveys. American Journal of Public Health, 93(2), 200-209.

Winship, C., \& Radbill, L. (1994). Sampling weights and regression analysis. Sociological Methods and Research, 23, 230-257.

Yonezawa, S., Wells, A. S., \& Serna, I. (2002). Choosing tracks: "Freedom of Choice" in detracking schools. American Educational Research Journal, 39, 37-67. 